\title{
ARBITRAJE DE COMPAÑÍAS SEVILLANAS (SIGLOS XVIII-XIX)
}

\author{
JESÚS JiMENO-BORRERO*
}

\begin{abstract}
RESUMEN
El presente estudio analiza el desarrollo del arbitraje societario en Sevilla en un momento histórico-jurídico crucial como es el paso de la dispersión de textos legales mercantiles del siglo XVIII a la unicidad del primer Código de Comercio en 1829. La variedad de fuentes consultadas niegan la interpretación del arbitraje como un método alternativo de solución de conflictos y demuestra su condición de sistema obligatorio dentro de la propia dinámica de la justicia consular para algunas materias societarias como la contabilidad. Por otra parte, este trabajo demuestra la impermeabilidad de la casuística mercantil a las diferentes influencias legislativas que se suceden desde el siglo XVIII hasta 1868.
\end{abstract}

PALABRAS CLAVE: arbitraje, codificación mercantil, compañía de comercio, resolución de conflictos, sociedad mercantil

*jimenoborrero@gmail.com 


\title{
ARBITRATION OF THE TRADE COMMERCE IN SEVILLE (XVIII-XIX CENTURIES)
}

\author{
JESÚS JiMENO-BORRERO*
}

\begin{abstract}
This article makes an in-deep analysis of commercial law arbitration in Seville during a historical and legal important time such as the codification, from very disperse commercial laws of XVIII century to the single-body Commercial Code of 1829. Several sources checked deny arbitration was just an alternative dispute resolution, therefore, arbitration was compulsory within the commercial system for some company law branches, such as accountability. Otherwise, this paper shows commercial law was not heavily influenced by different laws and legal reforms during XVIII century up to 1868.
\end{abstract}

KEYWORDS: arbitration, trade company, commercial codification, conflicts resolution, commercial partnership

*jimenoborrero@gmail.com 


\section{UNA OBSERVACIÓN PRELIMINAR ${ }^{1}$}

El presente trabajo aborda el estudio del arbitraje mercantil desde una perspectiva diferente a aquellos estudios reduccionistas que asemejan el arbitraje actual al arbitraje jurídico-mercantil desde una perspectiva histórica. No pueden compararse en un sentido estricto ambas instituciones a pesar de sus semejanzas, puesto que el árbitro de los siglos XVIII y XIX, lejos de reducir su actividad a un laudo en el que ganar celeridad y simplificar el procedimiento, realidad o acto que también ejerció, cumplía con otras funciones deudoras del arcaico ius mercatorum, ampliándose al intento denodado del acuerdo y del pacto en base a ciertos valores como el desprecio de la clase mercantil a la litigiosidad real, el buen nombre y la confianza, donde los mismos hombres prácticos del comercio asumían la función arbitral en correlato con la titularidad de los puestos representativos en el Consulado de Comercio de la ciudad.

El presente estudio sobre el arbitraje de los siglos XVIII y XIX se ha desarrollado atendiendo a una pluralidad de fuentes -legislativa, documental y doctrinaria- descartando la utilización de la jurisprudencia coetánea como otra fuente más, ya que los conocidos hoy como laudos arbitrales o las sentencias dictadas ambas por jueces legos resolvían los procedimientos abiertos en apenas unas breves líneas en los que no se aportan generalmente datos de interés.

Destaca fundamentalmente los contratos de compañía extraídos de los protocolos sevillanos, sitos en el Archivo Histórico Provincial de Sevilla, donde sus correspondientes cláusulas han aportado un conocimiento directo de la forma en que se desarrollaba la casuística comercial sobre diferentes aspectos del arbitraje, delimitando y conformando los contornos de un derecho vivo y latente como es el derecho mercantil en virtud del principio de libertad de pactos ${ }^{2}$.

Esta riqueza de fuentes nos ha permitido aproximarnos de forma completa y pormenorizada a una institución de tantos matices como el arbitraje

1. Abogado y Doctor en Derecho con mención Internacional (Universidad Carlos III de Madrid). Profesor Asociado del Departamento de Derecho Público I y Ciencia Política de la Universidad Rey Juan Carlos y Profesor Sustituto Interino del área de Derecho Constitucional de la Universidad de Huelva. Email: jimenoborrero@gmail.com. Orcid: https://orcid.org/0000-0002-8267-4038.

2. Sobre esta idea del derecho vivo del diritto commerciale y sujeto permanentemente a cambios propios de la dinámica económica encontramos las páginas de P. Grossi (2009), 9-18. 
de la época seleccionada y también ha deparado la división estructural del trabajo en dos partes de desigual extensión temporal. En primer lugar, el período previo a la codificación mercantil que abarca desde la creación de la Real Compañía por acciones de San Fernando en 1747 hasta la promulgación del primer Código de Comercio en 1829. Y en segundo lugar, desde la aprobación del citado Código de Comercio de 1829 y la inmediata Ley de Enjuiciamiento de los Negocios y las Causas de Comercio de 1830 hasta la aprobación en 1868 del Decreto de Unidad de Fueros que unifica los fueros civiles y mercantiles y, por tanto, la propia institución arbitral ${ }^{3}$. Una división temporal que tiene más de pura teoría doctrinal que fractura en la práctica societaria, comúnmente renuente a la afectación legislativa en la voluntad de las partes.

Este extenso período nos ha permitido comprender la forma en que el contrato de sociedad y la voluntad de los socios ha ido desarrollando, interpretando y modulando las cláusulas relativas al arbitraje, suponiendo una fórmula fehaciente de demostrar, en primer lugar, cómo se desarrollaba en la práctica el arbitraje societario y, en segundo lugar, cómo de permeable era la casuística sevillana a las influencias legislativas que durante el período temporal estudiado se suceden vertiginosamente.

Antes del primer Código de Comercio español continúan los diferentes proyectos de ordenanzas consulares como las del Proyecto fallido de Nuestra Señora de la Inmaculada Concepción ${ }^{4}$, el Consulado Nuevo de Sevilla de $1784^{5}$, la previa existencia de las Ordenanzas del Consulado de Bilbao en 1737 y otros tantos proyectos en ciudades andaluzas como las extensas ordenanzas del Real Tribunal del Consulado de Cádiz en 1800 y el proyecto consular malagueño de 1828 coetáneo al primer proyecto de Código de Comercio realizado por una Comisión legislativa en $1828^{6}$. Y primordialmente la llegada del Código de Comercio en la fecha señalada, en la que a pesar de

3. M. Olivencia (2014); (2006), 12-14.

4. Sobre este proyecto y su análisis desde una perspectiva societaria, C. Petrt (2016), 199-204; J. JiMENO-BorRero (2020), 50-51.

5. Encontramos noticias sobre el Consulado Nuevo de Sevilla en diferentes trabajos, A. Heredia Herrera (1985); P. Ortego Gil (1999) 167-201.

6. C. Petit (1980), 251-255. Analiza la práctica mercantil bilbaína y el propio texto legislativo con extensión directa a la institución arbitral. El mismo autor estudia los proyectos de ordenanzas de Cádiz y Málaga en (2016), 199-204. Igualmente sobre el proyecto de Código de Comercio de la Comisión Legislativa presidida por Sainz de Andino y los diferentes avatares que surgieron su redacción y su actuación desleal, C. Petit (2013a), 109-151; (2013b), 489-506. 
su carácter teóricamente coactivo para todo el territorio nacional, la práctica societaria determina en virtud de la fuerza de la autonomía de la voluntad la forma del arbitraje, sirviéndose los socios, escribanos y abogados del texto legal más como una fuente en el que fundar sus pretensiones que como el único texto que unívocamente regulaba el contrato de sociedad ${ }^{7}$.

\section{UNA JUSTICIA MERCANTIL}

El recurso al arbitraje no fue solo acción e intervención de la clase mercantil, sino que los mecanismos arbitrales suponen un recurso general que abarca pleitos y desavenencias de distinta naturaleza y justiciable de diversas cualidades según el momento histórico, participando de esta forma de resolución de conflictos las elites subjetivas desde la época romana o el período bajomedieval ${ }^{8}$, períodos en los que el término árbitro adquiere verdadero significado y en el que se irá solidificando la tradicional distinción recogida en el derecho de Partidas entre los jueces avenidores y los arbitradores o comunales amigos. Los primeros para referirse a los árbitros de derecho que deciden con arreglo a las leyes y los segundos para definir aquéllos que sustancian las desavenencias según su leal saber y entender sin necesidad de sujetarse a las disposiciones y formas legales ${ }^{9}$. Esta distinción entre las diferentes formas de ser árbitro ayuda al surgimiento de la problemática en la interpretación reduccionista del arbitraje actual al procedimiento arbitral histórico como también lo demuestra el uso por parte de los árbitros del término sentencia, propia de una justicia de raíz consular, a diferencia del término laudo.

Interesantes trabajos han abordado el estudio de la institución arbitral de forma general, partiendo de la idea de arbitraje como una justicia alternativa al régimen clásico y tradicional del pleito defendido por letrado y enjuiciado bajo la jurisdicción real ${ }^{10}$.

7. E. AвÁsolo (2008-2009), 447-460, reconoce esta interpretación del Código del Comercio como una fuente más en la dinámica del derecho del Antiguo Régimen.

8. Algunos ejemplos encontramos en A. Fernández de Buján (2011); L. Martone (1984), 72-127; V. Pérez Royo (2016), 145-195.

9. A. Merchán Álvarez (1981), 133ss y 176-177; J. de Vicente (1842), 75-76 expone esta diferencia al hablar de los distintos tipos de árbitros en el derecho mercantil.

10. Aunque son numerosos, ejemplificamos con diferentes publicaciones encabezadas por A. Merchán Álvarez (1981), 95-98, donde también aborda la cuestión mercantil, en concreto, la regulación de las Ordenanzas Bilbaínas. I. Cervantes Bravo (2015), 153175. Y el citado V. Pérez Royo (2016), 145-195. 
El arbitraje societario de los siglos XVIII y XIX no es forma residual de solución del desencuentro contractual mercantil, ni método alternativo a la jurisdicción real ${ }^{11}$, sino la forma legalmente prescrita para que los socios y compañeros resuelvan sus diferencias surgidas en el seno de la casa comercial ${ }^{12}$, lejos de apreciaciones bibliográficas que la consideran una materialización de la libertad de pactos; la persistencia de la legislación en su obligatoriedad viene a demostrar su naturaleza esencialmente prescriptiva. El arbitraje incorporado a ese engranaje interrelacionado del sistema consular en el que la justicia mercantil del Consulado y el arbitraje se entrecruzan como un sistema perfecto, producto del devenir de los tiempos, en el que la originaria separación procesal del ius mercatorum del derecho general alcanza su perfección técnica ${ }^{13}$.

\section{ARBITRAJE DE COMPAÑIIAS SEVILLANAS ENTRE 1747 Y 1829}

En la línea de lo descrito anteriormente, el arbitraje es el método prototípico para la resolución de conflictos mercantiles durante el tránsito al derecho codificado. La obligatoriedad de acudir al arbitraje en materia del derecho de contratos societarios se remonta al derecho de Partidas especialmente cuando la disputa se cierne sobre la materia contable ${ }^{14}$.

11. Entre otras cosas, porque la forma supuestamente tradicional no sería la justicia monárquica, sino la justicia consular, impartida por juez lego, en un proceso ágil, dinámico, sumario, donde la intervención letrada levantaba suspicacias entre las partes. Sobre esta cuestión, A. Mora Cañada (1988a), 355-367; (1988b), 629-638. R. Franch Benavent (1986).

12. Sin pretender adelantar los resultados del trabajo, los proyectos de ordenanzas Consulares y el Código de Comercio de 1829 (arts. 323 y 324) obligan a los compañeros a acudir a la vía arbitral para resolver los litigios de la compañía de comercio. Y no solo los textos legales, la rica casuística sevillana corrobora en sus contratos como los socios establecen una suerte de compromiso mediante el cual se acude a los árbitros, jurisárbitros, amigables componedores, sin que exista la posibilidad de que se pueda acudir a la supuesta "jurisdicción ordinaria" consular.

13. Conviene explicar que el germen del derecho mercantil no fue de naturaleza sustantiva, sino procesal como privilegio y reclamación permanente de una clase que exigía otras características debido a las demandas del tráfico comercial. Este origen procesal explica las especialidades en la resolución de conflictos mercantiles desde el citado ius mercatorum hasta la posterior entrada en vigor de la codificación mercantil. Sobre esta cuestión encontramos un extenso desarrollo en C. Petit (2016), 125-132. Y sobre la relación histórica del arbitraje con el nacimiento procesal del derecho mercantil, $\mathrm{M}$. Olivencia (2014), 10-12.

14. Partidas 5, título 10, ley 5. 
Un arbitraje forzoso que se prolonga durante todo el siglo XVIII en el derecho español. Las Ordenanzas del Consulado de Bilbao de 1737 (capítulo 10, ley 16) de aplicación subsidiaria en los Consulados erigidos bajo la corona española imponen por influencia de las Ordenanzas de Colbert de 1673 la vía del arbitraje para las controversias nacidas en torno a las cuentas:

Y porque al fin de las Compañías, estándose ajustando sus cuentas, se suelen suscitar entre los interesados de ellas muchas dudas, y diferencias de que proceden pleytos largos, y costosos, capaces de arruinar á todos, como la experiencia lo ha mostrado; por evitar semejantes daños, y para que las tales dudas, diferencias y pleytos sean decididos sumariamente, se ordena: que todos los que formaren Compañía, hayan de capitular y poner clausula en la Escritura que de ella otorgaren, en que digan, y declaren, que por lo tocante á las dudas, y diferencias, que durante ella, y á su fin se les puedan ofrecer, se obligan y someten al juicio de dos, ó más personas prácticas, que ellos, ó Jueces de oficio nombraren, y que estarán, y pasarán por lo que sumariamente juzgaren, sin otra apelación, ni pleyto alguno; cuya clausula se les hara guardar, y observar, baxo de la pena convencional, que también deberán imponerse, ó la arbitraria que los Jueces les señalaren ${ }^{15}$.

Los contratos analizados se decantan por el pacto genérico de sumisión al arbitraje. Son los supuestos entre otros de: Manuel Rufo y Compañía ${ }^{16}$, viuda de Arambillague y Richards ${ }^{17}$, o D. Gregorio Martínez y Sobrino ${ }^{18}$. Sin embargo, existen ejemplos de contratos con carácter

15. Sobre las influencias de las Ordenanzas francesas de Colbert de 1673 en las Ordenanzas del Consulado de Bilbao encontramos noticias en C. Petit (1980), 250-251.

16. D. Manuel Rufo y Comp. ${ }^{a}$, Archivo Histórico Provincial de Sevilla (AHPS), legajo 6539, fols. 58-63, Sevilla, 1819: “15 Que si hubiere algun disgusto ó desabenencia, entre nos las dichas partes compañeras que no lo esperamos, desde luego para entonces, nos comprometemos, en nombrar por Jueces, Arbitros, arbitradores, y amigables componedores, dos personas bien inteligentes, en semejantes tratos, y Dependencias, $\mathrm{p}^{\mathrm{a}}$ que esta decidan lo justo que decidan sobre ello y en el caso de discordia nombraremos un tercero, y estaremos precisamente por lo que este decida y determine (...)".

17. Viuda de Arambillague y Richards, AHPS, legajo 6549, fols. 503-505, Sevilla, 1826: "7a Que si hubiera alguna duda disgusto ó desavenencia entre nos los referidos dos socios desde luego para entonces nos comprometemos en nombrar por Jueces, Jurisarbitros, arbitradores y amigables componedores á dos sujetos imparciales de providad é inteligentes en semejantes dependencias para que estos desidan lo que encuentren justo sobre ello, y en caso de que estos no se avengan nombren otro sujeto para que decida el punto ó particulares en que discorden; y á lo que estos hagan precisamente hemos de estar".

18. Gregorio Martínez y Sobrino, AHPS, legajo 6549, fols. 84-87, Sevilla, 1826: "9a Que 
minoritario cuyas cláusulas acuerdan el cumplimiento exhaustivo de los preceptos citados refiriendo expresamente que cuando la disputa tenga como objeto las cuentas de la compañía se acuerde la intervención de árbitros nombrados por cada socio. Algunos ejemplos son José Antonio Pevidal y Compañía ${ }^{19}$, o la sociedad Marruella / Nieto, en las que se aprecia que el pacto se centra en la posibilidad de que las cuentas no estén suficientemente claras en los supuestos de separación o de elaboración de la cuenta final ${ }^{20}$.

Las fuentes utilizadas y la profunda búsqueda realizada en el Archivo Provincial de Sevilla (Sección Protocolos) nos ha permitido encontrar un caso práctico de arbitraje societario fundado en la problemática contable de la compañía como se observa en la disolución de Francisco Ruiz Toranzo y Compañía, en la que se otorga poder al árbitro, bajo la denominación de "inteligentes en los negocios", para el registro y reconocimiento de los "libros y papeles de la compañía":

si hubiera alguna duda disgusto ó desavenencia entre nos los referidos dos socios desde luego para entonces nos comprometemos en nombrar por Jueces, Jurisarbitros, arbitradores y amigables componedores á dos sujetos imparciales de providad é inteligentes en semejantes dependencias para que estos desidan lo que encuentren justo sobre ello, y en caso de que estos no se avengan nombren otro sujeto para que decida el punto ó particulares en que discorden; y á lo que estos hagan precisamente hemos de estar".

19. Don José Pevidal y Compañía, AHPS, legajo 1851, fols. 520-523, 1823: "El Decimo tercio: Que si a la conclusión de esta sociedad hubiera algun disgusto por cualquiera de los otorgantes en nuevas cuentas finales, desde ahora hasta entonces, nos comprometemos a juntos a estar, y pasar por la transacción que hagan dos hombres de buena conciencia del comercio de esta ciudad, que se nombrarán uno por cada parte, y tercero elegido de acuerdo de ambos, en caso de discordia, para lo que de conformidad los autorizamos con el compesente poder que legalmente se requiera, obligandonos a estar, y a pasar por su dictamen, y resolución sin podernos oponer con protextos alguno a ellas, bajo las multas, o pena combencional que nos imponemos mutuamente".

20. Compañía Marruella / Nieto, AHPS, legajo 3830, fols. 1304-1307, Sevilla, 1826: “3”. Que si durante el tiempo de esta sociedad, se promobiere alguna diferencia y motibo fundado, que calificaran dos advitros q para ello nombraran cada uno de los comparecientes y en caso de discordia el tercero q estos eligieren. Que si quisiere alguno de los dos socios disolver o concluir esta compañía ante el tiempo prefixado estando de acuerdo ô habiendo justa causa para ello según el dictamen de los arvitros sin necesidad de diligencia alguna judicial se verificará indicada separacion integrandose primeramente al Marella de todos los fondos $\mathrm{q} \mathrm{p}^{\mathrm{a}}$ dicha sociedad hubiere puesto aunque ecceda de los repetidos cincuenta mil reales en atencion a lo que se dira en la clausula siguiente siendo presisa cualidad de que la reintegracion de dicho capital hace ser presisamente en efectivo metalico plata û otro contante y sonante y no otra especie qualquiera de la clase que fuese". 
Lo primero, que en el dia veinte y nueve de Julio ultimo passado se ajusto y liquido la Cuenta final de dicha Compañía de todo el tiempo que a estado con nuestra asistencia personal y la de Don Marcos Larín vecino de esta Ciudad a quien como inteligente nombramos de conformidad como tercero de orden de Don Joseph de Mier vecino y del Comercio de ella a cuya elección lo dejamos para que reconociesse y rexistrasse todos los Libros y papeles de dicha Compañía y verificasse y cotejase con ellos la Cuenta que se formó de ella y en una forma se ajustó y halló cual fiel y legal a nuestra entera satisfacción sin agravio de parte por lo que todos tres los firmamos quedandose cada uno de ambos otorgantes atento a que se extendió por duplicada con una por lo qual aprobamos ratificamos en todo y por todo como en ella se conviene para que siempre sea firme y valida y conste no se nos a ofrecido reparo alguno en quanto expresa ${ }^{21}$.

El clausulado del contrato de compañía surte efectos obligatorios de compromiso por el que los socios se someten a la intervención arbitral y que suele contener un pacto general estandarizado a través del formulario del escribano que consiste en el nombramiento genérico, excepcionalmente

21. Disolución de Francisco Ruiz Toranzo y Compañía, AHPS, legajo 1346, fols. 285-286, 1760. La limitación de la extensión del presente trabajo nos impide extendernos con el documento notarial que acuerda la disolución de la compañía, aunque conviene precisar que el pacto incluye en las restantes cláusulas la forma fehaciente en la que se repartían las ganancias obtenidas y se resarcían las deudas contraídas. Reproducimos una parte de la cláusula segunda por su indudable interés, aunque su extensión nos impide hacerla de forma completa: "Lo segundo en atención a que de la citada Cuenta a resultado aver suficiente Caudal assi para la satisfacción del Capital de los trece mil doscientos ochenta y dos Reales de Vellon a mi el referido Don Joseph Gutierrez como para la de lo que se debe por dicha Compañía a Don Miguel de Obredo vecino y del Comercio de la Ciudad de Cadiz y para que ambos otorgantes participemos de algunas ganancias yo el dicho Don Joseph Gutierrez declaro aver recibido del expresado Don Francisco Ruiz Toranzo el importe de dicho Capital a mi perteneciente en esta forma: siete mil novecientos y noventa, y ocho Reales de Vellón en dinero efectivo, y lo restante que son cinco mil doscientos sesenta y nueve Reales y seis libras y media de Arroz a precio cada quintal de setenta Reales de la misma moneda que ambas partidas componen los referidos trece mil docientos ochenta, y dos Reales de Vellón impone de dicho mi Capital en ya conformidad de todos ellos me doy por contento satisfecho, y en acuerdo a mi voluntad sobre que renuncio la excepción, y Leyes de las no numera pecunia prueva del encargo y recivo como en ellas se conviene, y le otorgo Carta de Pago, en la mejor y mas bastante forma, que a su derecho y seguridad convenida o tercero en atención a que a mi el referido Don Joseph Gutierrez me an tocado según la citada Cuenta por mi mitad de ganancias del procedida de dicha Compañía nueve mil trescientos ochenta y siete Reales y medio de Vellón quien nos como la otra mitad al referido D. Juan Ruiz Toranzo (...)". 
realizado y singularizado en el propio contrato, de dos árbitros que ante los posibles desacuerdos o desavenencias entre ambos y ante la imposibilidad de acordar una solución definitiva, éstos se encuentran autorizados para el nombramiento de un tercero que resuelva el contencioso ${ }^{22}$. Aunque en la práctica contractual sevillana encontramos excepcionalmente ejemplos de compañías que articulan un procedimiento más sencillo con un solo árbitro al que debe pasársele nota escrita de lo sucedido y éste resuelve lo más conveniente para la sociedad ${ }^{23}$.

Esta dualidad arbitral que se produce unánime y uniformemente en la práctica sevillana no se identifica con otros resultados casuísticos como los de Bilbao o Valencia donde se muestra mayor variedad en cuanto al número de árbitros ${ }^{24}$. Una realidad jurídico-mercantil que pudiera ser manifestación de los diferentes textos legislativos como el ya reproducido precepto de las Ordenanzas del Consulado de Bilbao $(10,16)$ y principalmente la ley 27 de las Ordenanzas del Consulado Nuevo de Sevilla erigido en 1784:

El Prior y Cónsules, ó dos de los tres, formarán el Tribunal con jurisdicción y facultad privativa para conocer y terminar todas las diferencias y pleytos que ocurran entre Hacendados, Comerciantes, Mercaderes, y dueños de fábricas y embarcaciones, sus factores, encomenderos y dependientes, estén ó no matriculados éstos, sobre ventas, compras y tratos puramente mercantiles, portes, fletes, averías, quiebras, compañías, seguros, letras, y demás puntos relativos al comercio de tierra y mar, oyendo á las partes interesadas á estilo llano, la verdad sabida, y buena fé guardada, sin admitir pedimentos ni alegaciones de Abogados.

Unas influencias que demuestran que en materia de número de árbitros en el siglo XVIII la omnívora libertad del pacto mercantil se encuentra limitada y cercada por la legislación y el formulario del escribano público. El número de árbitros y la sistemática que según las escrituras se seguía en el arbitraje nos hace adentrarnos en el proceso. Un proceso que no puede

22. Podemos afirmar que esta forma de solución de la controversia opera en un $80 \%$ de los contratos analizados, sirvan como ejemplos los siguientes contratos ya reproducidos parcialmente: D. Manuel Rufo y Compañía, Marruella / Nieto, Viuda de Arambillague y Richards, o Gregorio Martínez y Sobrino.

23. Como se aprecia en Barea / Escacena, AHPS, legajo 3827, fols. 155-160, Sevilla, 1817: " 3 a. Todas las consultas que no queden resueltas entre los Asentistas y que nesesiten del parecer de una tercera persona, pondran por escrito cada uno su pareser, y los dos pareseres se entregaran a la persona que haya de decidir (...)".

24.C. Petit (1980), 252-253; A. Mora Cañada (1988), 355-367. 
calificarse de anárquico, a pesar de la dinámica abierta que se recoge en la escrituras y del general rechazo a la intervención letrada ${ }^{25}$. El procedimiento arbitral en analogía con los principios de la jurisdicción mercantil se caracteriza por un procedimiento ágil, breve y sumario en el que no se suele distinguir fases procedimentales en un sentido estricto, salvo la referida división entre los dos árbitros nombrados por cada socio y el tercero que resultaría decisorio.

La verdad sabida, presunción de hecho admitida a efectos de valorar la prueba, y la buena fe guardada por los hombres inteligentes en el Comercio eran los contrapesos a la ausencia de formalismos y a la inexistencia de un juicio propiamente dicho ${ }^{26}$.

A diferencia de las discusiones doctrinales sobre la naturaleza y los efectos de los distintos árbitros, ya sean de derecho o de equidad, amigables componedores, las escrituras de sociedad se decantan por la remisión arbitral bajo todas sus posibles acepciones o denominaciones: jueces, árbitros, arbitradores, jurisarbitros y amigables componedores, sin que se preste atención a la división establecida por la literatura jurídica ${ }^{27}$.

En los contratos estudiados, la remisión general del pacto a la futura elección del árbitro se adiciona en ocasionas al establecimiento de una

25. Las ordenanzas del Consulado Nuevo de Comercio de Sevilla admiten la prueba escrita junto con los documentos, pero sin intervención letrada; ley 29: "Si el negocio fuere de difícil prueba, y alguna de las partes pidiere audiencia por escrito, se le admitirá el memorial firmado con los documentos que presente, sin intervención de Letrado, y con solo la respuesta en los mismos términos de la otra parte se procederá á la determinación dentro de ocho días". A. Merchán Állvarez (1981), 173 y ss., recoge el normal rechazo de los sometidos al arbitraje a usar alegaciones fundadas en derecho.

26. Sobre el proceso mercantil del siglo XVIII, A. Mora CAÑAda (1988), 629-638.

27. Son los supuestos por ejemplo de los contratos mencionados anteriormente y también de todos los demás contratos estudiados como por ejemplo Eugenio Lara, Menor y Eugenio de Lara, Menor y Compañía, AHPS, legajo 6530, fols. 739-741, Sevilla, 1810: " $11^{\text {a }}$. Que si hubiera algun disgusto ó desavenencia entre nos los ambos dichos dos otorgantes. Que desde luego para entonces nos comprometemos en nombrar por Jueces, Jurisarbitros, arbitradores y amigables componedores dos sujetos bien ynteligentes $\mathrm{p}^{\mathrm{a}}$ que estos desidan lo justo que jusquen srê ello, y en el caso de discordia nombraremos un tercero y estaremos precisamente â lo que este decida y determine (...)", o González y Fernández, AHPS, legajo 6539, fols. 463-466, Sevilla, 1819: “12a. Que si por algun ebento pensado durante el tiempo de este establecimiento, ó á el de su conclusión ó separación hubiese algun disgusto ó desabeniencia entre nos las dichas partes compañeras que no lo esperamos, desde luego para entonces nos comprometemos en nombrar por Jueces, Juris, arbitros, arbitradores, y amigables componedores dos personas bien inteligentes en semejantes tratos y Dependencias (...)". 
multa a aquel socio que rehúsa el arbitraje o que aceptándolo decide posteriormente rechazar el fallo de los árbitros. En la casuística sevillana no se establece el quantum indemnizatorio y el compromiso refiere la imposición de una multa "combencional"28; la sanción impuesta es una manifestación tradicional del ius mercatorum por acudir a las justicias reales o establecer un recurso de apelación al laudo dictado por los árbitros nombrados ${ }^{29}$.

Se trataba al fin y al cabo de evitar la prolongación innecesaria de un procedimiento que perjudicaba al giro mercantil y a la celeridad necesaria para proseguir el sostenimiento de la casa familiar y de comercio. Por ello, no fue excepcional que los contrayentes establecieran un plazo máximo para la terminación del pleito como sucedió en el dieciochesco Consulado de Comercio de Valencia ${ }^{30}$. La casuística sevillana estudiada

28. Son los casos de las siguientes escrituras; Carlos Solaxo Coene y Comp ${ }^{\mathrm{a}}$, AHPS, legajo 2877, fols. 12-14, Sevilla, 1762: “(...) pues en el caso de dicha discordia dudas ó diferencias que puedan acaeser durante dicho tiempo, su dessicion y determinacion la émos de determinar por lo que dispusieren y ordenaren el arvitro ó arvitros y amigable componedores sujetos practicos, y comerciantes personas que por nosotros fueren nombradas $\mathrm{p}^{\mathrm{a}}$, ello cuyo dictamenes emos de aprovar, y nos an de obligar á estar y pasar por ello vaxo de las penas apersivimientos y demas que derecho haya lugar". Compañía Marruella / Nieto, AHPS, legajo 3830, fols. 1304-1307, Sevilla, 1826: “13a. (...) y se obligan â estar por lo que determinen obserbandose asi en todos los puntos y diferencias que ocurran en la manera que se han sentado $\mathrm{p}^{\mathrm{a}}$ el caso de separacion según la clausula tercera y a mayor abundamiento que se les condene en las costas y cualesquiera otro perjuicio que se les siga y cause por falta de cumplimiento del que no estubiere conforme". D. José Pevida y Compañía, AHPS, legajo 1851, fols. 520-523, Sevilla, 1823: “El Decimo tercio: (...) y tercero elegido de acuerdo de ambos, en caso de discordia, para lo que de conformidad los autorizamos con el compesente poder que legalmente se requiera, obligandonos a estar, y a pasar por su dictamen, y resolución sin podernos oponer con protextos alguno a ellas, bajo las multas, o pena combencional que nos imponemos mutuamente". La praxis bilbaína regula ordinariamente las cuantías previstas por acudir por la vía judicial que oscila entre los 400 pesos y los 60.000 reales; C. Petiт, La compañía mercantil..., p. 253.

29. La regla general de la inapelabilidad del lauda arbitral encuentra con carácter extraordinario excepciones desde el derecho de Partidas como el "recurso de reducción a albedrío de buen varón" frente al laudo donde los jueces de avenencia hubiesen juzgado con engaño, A. Merchán Álvarez (1981), 261-262, y R. Hinojosa Segovia (1991), 10-11. Las mismas leyes de Partidas (Partida 3, tít. 4, ley34) establecen la opción de recurrir en base a dos recursos, el general de apelación y el de nulidad por haber incurrido en un defecto grave como haber sido dictado por árbitros no sujetos al compromiso o por estar éstos recusados.

30. A. Mora CAÑADa (1988), 355-367, aunque el procedimiento arbitrado no siguiera una regulación procesal especializada con el objeto de acelerar la resolución del conflicto, también podía realizar sucesivas ampliaciones del período probatorio que llevan a alargar el pleito. 
del siglo XVIII adolece de pactos que cifren un período máximo para la terminación del procedimiento, aunque por analogía con las ordenanzas del Consulado Nuevo de Sevilla de 1784 y por la propia naturaleza del negocio mercantil consideramos que debieron existir cláusulas contractuales exigiendo tal empresa ${ }^{31}$.

Cabe plantearse ahora cuáles fueron las cualidades personales que debían reunir los árbitros. El principio unánime ofrecido por los contratos refieren la exigencia de la experiencia y el conocimiento en las dependencias comerciales bajo un uso terminológico distinto como González y Fernández: "desde luego para entonces nos comprometemos en nombrar por Jueces, Juris, arbitros, arbitradores, y amigables componedores dos personas bien inteligentes en semejantes tratos y Dependencias", D. Gregorio Martínez y Sobrino: "nos comprometemos en nombrar por Jueces, Jurisarbitros, arbitradores y amigables componedores á dos sujetos imparciales de providad é inteligentes en semejantes dependencias", y Viuda de Arambillague y Richards: "la émos de determinar por lo que dispusieren y ordenaren el arvitro ó arvitros y amigable componedores sujetos practicos, y comerciantes personas que por nosotros fueren nombradas".

Por último, esta visión del arbitraje mercantil sujeto al imperativo legal y al estándar del formulario del escribano público no debe interpretarse como la limitación absoluta de la regla de la libertad de pactos, sino como un diálogo permanente entre la ley, la costumbre y la praxis mercantil en la que como siempre es habitual en la naturaleza contractual toma fuerza la voluntad de los partícipes. Es el supuesto de la sociedad Acebedo / Del Real, en la que ante las posibles desavenencias entre las partes uno de los socios, Hermenegildo del Real, se erigirá en árbitro y decidirá lo más conveniente para el interés social:

31. Las diferentes leyes de las Ordenanzas del Consulado Nuevo de Sevilla establecen un breve plazo para sustanciar, en primer lugar, el procedimiento en un plazo de quince días; ley 30: "En los negocios de mayor cuantía se admitirá el recurso de apelación á la parte agraviada para el Asistente, quien en dos adjuntos nombrados respectivamente entre otros dos matriculados, que el propondrá cada una de las partes litigantes, substanciará y determinará el pleito con un solo traslado, sin alegatos ni informes de Abogados, en el término preciso de quince días haciendo sentencia dos votos conformes", y en segundo lugar, para que el Juez de Alzadas revisen el pleito en nueve días; ley 31: "Si la sentencia dada fuere conforme á la del Consulado, se executará sin recurso; pero siendo revocatoria en el todo ó parte, podrá suplicarse de ella, y en el término preciso de nueve días reveerán y sentenciarán el Juez de Alzadas y otros dos adjuntos el pleyto, y con lo que determinen se executoriará". 
Que de tres en tres meses tengo yo el don Ignacio Acebedo los devidos reconocimientos, los devidos reconocimientos, en la dicha Casa Almacen de Bebidas, $\mathrm{p}^{\mathrm{a}}$ ver el estado de las existencias é intereses de ella, y si en el caso no esperado encontrare defalco en dicho don Hermenegildo sere arbitro, como desde ahora $\mathrm{p}^{\mathrm{a}}$ entonces lo quedo $\mathrm{p}^{\mathrm{a}}$ deshacer dicha compañía $(\ldots)^{32}$.

Una cláusula que demuestra el vigor de la regla del intuitus personarum, de la confianza recíproca y de la capacidad para elegirse entre unos compañeros a quienes se les faculta con unas potestades, como decidir cuándo sé es parte del asunto, que hoy nos resulta sorprendente.

\section{ARBITRAJE DE COMPAÑÍAS SEVILLANAS ENTRE 1829 Y 1868}

Aun con una fecha sensiblemente anterior a la aprobación del primer Código de Comercio, debemos iniciar el presente epígrafe con la constitucionalización de la figura del arbitraje en la Constitución doceañista de Cádiz, indistintamente de su naturaleza y ligado de forma más o menos expresa a las libertades del proyecto liberal que se prolongará durante el siglo XIX en España ${ }^{33}$.

El estudio del arbitraje en el período codificador presenta un elemento de especial interés por cuanto permite comprender y replantear las posibles variaciones que la aprobación y promulgación del Código de Comercio realiza en el arbitraje societario. Para ello, hemos creído conveniente repetir el esquema del epígrafe inmediatamente anterior a efectos de poder desarrollar una comparación entre la praxis mercantil, la legislación y la doctrina que otorgue verdadero significado a la investigación realizada.

El Código de Comercio (art. 323) no altera el arbitraje forzoso de los compañeros cuando el germen del conflicto tenga su base en la contabilidad social. La importancia del artículo aconseja su reproducción íntegra por

32. Compañía Acebedo / Del Real, AHPS, legajo 2931, fols. 279-281, Sevilla, 1814.

33. La redacción de los artículos 280 y 281 de la Constitución de Cádiz no deja lugar a dudas de su carácter marcadamente liberal: "No se podrá privar a ningún español del Derecho de terminar sus diferencias por medio de jueces árbitros, elegidos por las partes" (art. 280); y "La sentencia que dieren los árbitros, se ejecutará, si las partes al hacer el compromiso no se hubieren reservado el derecho de apelar" (art. 281). Una constitucionalización del derecho arbitral indistinto a la naturaleza que influiría en el texto constitucional de otras latitudes de Ultramar como México. Sobre esta influencia, I. Cervantes Bravo (2015), 153-175. 
cuanto demuestra la continuidad de la legislación societaria manteniéndose impermeable a las influencias legislativas foráneas -principalmente francesas- como de la propia dinámica del proceso codificador: "Toda diferencia entre los socios se decidirá por jueces árbitros, háyase ó no estipulado en el contrato de sociedad".

La sociedad mercantil sevillana posterior a la promulgación del Código muestra la continuidad del modelo anterior en el que se combina la general cláusula del arbitraje con otros supuestos como Steinacher y Compañía o Agustín Henkes y Compañía en el que las partes se obligan a acudir al proceso arbitral cuando la disputa obedezca a cuestiones contables ${ }^{34}$. González Huebra, jurista mercantil más importante de la época, precisa que "la sumisión al juicio de árbitros para la decisión de las cuestiones la que se entiende siempre estipulada aunque no se haya expresado" en el contrato de sociedad $^{35}$. Otra opción que se halla en los papeles sevillanos refiere la posibilidad de solventar la separación y liquidación de la compañía bajo el auxilio de peritos nombrados por cada socio que calculen el justiprecio a abonarse $^{36}$.

El compromiso de las escrituras permanece inalterado al anterior período remitiéndose los interesados a un nombramiento a futuro de los socios, aunque existan excepciones al principio general como la sociedad Señores Viuda de Bartelemy y D. Fermín de la Puente y Apecechea donde los dos socios nombran a dos abogados pertenecientes al Ilustre Colegio de Abogados de Sevilla y a un tercero en caso de discordia entre los anteriores, otorgándoles

34. Agustín Henkes y Compañía, AHPS, legajo 2917, fol. 464-468, Sevilla, 1844: "Decimo setima. Que en caso de discordia llegado el de la liquidacion, se han de nombrar por ambos socios árbitros arbitradores, y amigables componedores que diriman las cuestiones que se suscitan (...)"; Steinacher y Compañía, AHPS, legajo 8832, fols. 671-680, 1846: " $16^{\mathrm{a}}$ Estas cuestiones que puedan ocurrir en las condiciones de este contrato en el modo de liquidar las cuentas de que se hablará en su lugar ó cualquiera que se promueba por cualquier incidente ó motivo se someten a la decision de los Juezes arbitros arbitradores y amigables componedores nombrados de conformidad por todos ellos ó cada uno el suyo".

35. P. GonzÁlez de la Huebra (1867), 131: "La sumisión al juicio de árbitros para la decisión de las cuestiones la que se entiende siempre estipulada aunque no se haya expresado, debiendo ser nombrados ó por los mismos interesados en el término que la escritura ó el tribunal les señale, ó por este de oficio, si alguno lo deja transcurrir sin haberlo verificado".

36. Suárez / Orozco, AHPS, legajo 878, fols. 376-377, 1844: "Cuando alguno de los otorgantes quiera separarse de la sociedad le abonará en este caso el que quede en ella lo que le corresponda por aprecio que se practique á cuyo objeto nombrará cada uno el suyo y pasarán por el justiprecio que hisieren los peritos nombrados". 
a ambos la facultad de nombrar a su propio sustituto en el supuesto que no pudiera intervenir como árbitros ${ }^{37}$. En este sentido, la doctrina prohíbe que se pueda delegar la condición de árbitro en otras personas a excepción que se les hubiera facultado en el compromiso ${ }^{38}$. Otros contratos se remiten, en caso de discordia entre los árbitros nombrados por las partes, a un tercero que ha podido ser "elegido a suerte, o por el Tribunal del Comercio" 39 .

El nombramiento de árbitros en el compromiso tampoco especifica la condición en la que son nombrados, sino que se remiten de forma genérica: jueces, árbitros, arbitradores, jurisarbitros y amigables componedores. González Huebra considera que los "jueces árbitros deben proceder con arreglo á las leyes de sustanciación en los asuntos que les competan", aunque las partes pueden "dispensarles de esta obligación, y autorizarlos para que procedan como arbitradores y amigables componedores, y decidan sus diferencias sin forma de juicio"40. Un ejemplo práctico encontramos en la casuística sevillana en la Cancelación de la compañía Parreño / Carreño donde los socios acuerdan contratar como "amigables componedores" para liquidar la cuenta de la compañía respecto de las arrobas de aceite molidas por uno de los consocios ${ }^{41}$.

37. Señores Viuda de Bartelemy y D. Fermín de la Puente y Apecechea, AHPS, legajo 874, fols. 508-513, 1843: " $20^{\circ}$ Aunque no es de creer que entre los socios existan nunca sino motivos de mutuo aprecio y amistad, en caso de desabenencias se zanjaran todas amistosa y estrajudicialmente comprometiendolas en arvitros, que lo seran por la persona a Viuda de Bartelemy el Dr. D. Diego Maria Guerrero, por D. Fermin de la Puente y Apezechea el Dr. D. Manuel del Amor Laraña y tercero en caso de discordia entre los dos el Dr. Don Andres Gutierrez Laborde Abogados del Ilustre Colegio de esta Ciudad vecinos de ello, con la pena de Reales vellon veinte mil para el que no se conformare con la decision. $21^{\circ} \mathrm{Si}$ alguno ó algunos de los arvitros no pudiere por fallecimiento, ausencia ó absoluta imposibilidad evacuar su encargo, los socios se compone en á nombrar dentro del termino de un mes otro ú otros que los reemplazen, en la inteligencia de que el que no lo hisiere, estará obligado á pasar por la decision del arvitro que quedare no pudiendo deducir en Juicio reclamacion ninguna los socios sin haberla previamente comprometido ante los arvitros ó los que en su caso nombrasen".

38. J. DE ViCENTE (1842), 82.

39. Señores Luque y Martínez, AHPS, legajo 2972, fols. 818-824, 1844: "Decimo setima. Que cuando ocurran diferencias disputas ó motivos de controversia hayan de decidirse por Jueces árbitros nombrados por las partes, y en caso de discordias por un tercero elegido á la suerte, ó por el Tribunal de Comercio".

40. P. González Huebra (1867), 130-132.

41. Cancelación de la compañía Parreño / Carreño, AHPS, legajo 1979, fol. 297, 1836: “(...) sentando en el todas las compañías que estimaron oportunas siendo una de ellas, siendo una de ellas que todos los fondos que entraren de dicha negociación habian de 
El proceso seguido en el arbitraje permanece inalterado como demuestra la aplicabilidad de los principios de la verdad sabida y la buena fé guardada, la brevedad y la sencillez en el Proyecto de Ordenanzas del Consulado de Málaga de 1828 , un proyecto lindante temporalmente a la promulgación del primer Código de Comercio $^{42}$.

La inexistencia general de un plazo máximo para la finalización del procedimiento arbitral encuentra su contrapeso en la limitación de aquellos supuestos que pudieran prolongar innecesariamente el proceso, principalmente cuando una de las partes acude a la vía estrictamente judicial imputándosele al mismo los gastos originados como sucede en la compañía Francisco Delgado ${ }^{43}$, o la tradicional multa por impugnar el laudo arbitral que puede revestir importantes cantidades como sucede en las sociedades

entrar en clase de deposito de poder de Don José Antonio Pevidal vecino y de Comercio de esta Ciudad bajo los oportunos Recibos; se berificó la recoleccion de el expresado fruto el que se molió y hizo Aceyte el que aunque se repartió la mayor parte de el, ambos Socios no estuvieron estos conformes en el numero de Arrobas producidas ni con la Cuenta que presentó el Don José Antonio Pevidal como tal Depositario, lo que dió motibo para que ambos Comparecientes, el Don José Antonio Pevidal Bernardo Garcia Vigil y los Maestros de Molino, que havian molido dicha Aceytuna pareciesen ante el Sr. Don Miguel Ruiz Martinez Teniente Alcalde de esta misma Ciudad a evaquar el oportuno juicio de Paz, como en efecto así verificó en el día once de Julio de este año de la fecha, en el cada uno dedujo su acción y derecho y no habiendo havido conformidad en estos particuares solo la hubo en que ambos comparecientes eligiesen cada uno en conforme en clase de Amigable componedor que decidiese en qualquier diferencia que hubiese entre ambos obligandose a estar y pasar por el Laudo que pronunciaren Don Fernando Parreño nombró por su parte en clase de compromisario a el Licenciado Don Antonio del Castillo Fabricante de Sedas vecino de esta Ciudad, y el Don José Carreño eligió por la suya en union con el Don José Antonio Pevidal a Don José Echeverria y López, quienes en diez y siete del propio mes y año aceptaron su encargo obligandose a evaquarlo en toda forma. En fuerza de las facultades que por ambos comparecientes se concedieron ambos compromisarios, evaquaron su encargo y en el dia veinte de Septiembre de este año de la fecha pusieron su laudo y sentencia, por el qual dijeron que el Don José Carreño debía entregar al Don Fernando Parreño tres y quinientos reales de vellon con cuya cantidad quedaba este completamente pagado y satisfecho".

42. Proyecto de Ordenanzas del Consulado de Málaga 1828, art. 243: "Los principios y reglas generales que rigen la administración de justicia en el tribunal del consulado son: verdad sabida y buena fe guardada en sus decisiones, sencillez y brevedad en sus procedimientos".

43. Compañía Francisco Delgado, AHPS, legajo 7235, fols. 66-69, Sevilla, 1847: "8a. Que si para el cumplimiento de todo ó parte de esta Escrt ${ }^{\mathrm{a}}$ se promoviesen diligencias judiciales serán de cuenta de quien de causa á ellas las costas que se originen aun cuando cumpla en el acto del primer requerimiento juicio de conciliacion ó verbal”. 
Caso / Sánchez y Señores Viuda de Bartelemy y D. Fermín de la Puente y Apecechea donde la multa por no conformarse con la solución dada por los árbitros asciende a la nada despreciable cantidad de veinte mil reales de vellón ${ }^{44}$.

Cuestión distinta es la relativa a las cualidades personales que deben poseer los árbitros nombrados por las partes, a excepción de los concertados por el contrato de la Viuda de Bartelemy y D. Fermín de la Puente, donde ambos son abogados adscritos al Colegio de Abogados de Sevilla, los restantes contratos solo relucen como exigencia común la práctica en negocios similares y el buen nombre ${ }^{45}$. Los requisitos del Código de Comercio (art. 1186) para ser juez del Tribunal del Comercio reproducen la regla contractual sevillana estableciendo como exigencia principal la experiencia comercial y la buena opinión, sin haber originado quiebra culpable ni mantener deudas con la Real Hacienda ${ }^{46}$.

\section{CONCLUSIONES}

La institución estudiada en los siglos XVIII y XIX se enmarca en una solución judicial plenamente inserta en la justicia consular mercantil del período estudiado, atribuyéndole una serie de facultades ajenas a la función

44. Caso / Sánchez: “(...) a cuyo fin renuncian a todos los recursos ordinarios y extraordinarios que contra la sentencia de aquellos y de este en su caso, pudieran entablar imponiendose desde ahora la multa de veinte mil reales vellon el que no se conformase contra la sentencia arbitral a favor de su consocio, sin que por esto se entienda que despues de satisfacer la pena pueda acudir a los medios judiciales pues expresamente le queda prohibido"; Señores Viuda de Bartelemy y D. Fermín de la Puente y Apecechea: " $20^{\circ}(\ldots)$ con la pena de Reales vellon veinte mil para el que no se conformare con la decisión".

45. Compañía Sainz de Arce / Díaz, AHPS, legajo 3879, fols. 817-818, Sevilla, 1837: "Cuarta: que ninguno de ambos otorgantes podremos faltar á lo pactado en este contrato sin que preceda una justa causa la que será calificada por dos personas del comercio elegidas una por cada interesado".

46. Código de Comercio 1829, art. 1186: "Los que hayan de ser jueces en los tribunales de comercio han de reunir las circunstancias siguientes: La ser natural de estos reinos, y haber cumplido treinta años de edad. 2. Llevar cinco años á lo menos en la matrícula, y ejercicio del comercio en nombre y con caudal propio. 3. Gozar de buena opinión y fama. 4. No haber hecho quiebra culpable: ni fraudulenta; y en el caso de haberla hecho inculpable i de suspensión de pagos, hallarse rehabilitado. 5. No haber sido condenado por delito á pena corporal aflictiva. No ser deudor líquido á la real Hacienda, ni á fondo alguno municipal. El prior ademas debe llevar, diez años de matrícula y ejercicio en el comercio, y haber sido anteriormente cónsul en propiedad ó sustituto". 
arbitral actual y distante a una interpretación estricta de solución alternativa de conflictos. El arbitraje viene legalmente prescrito por los diferentes cuerpos legislativos con el fin que los socios resuelvan sus diferencias societarias, aunque esta visión no significa la exclusión de la libertad de pactos de los contratos analizados que articulan acuerdos propios en base al citado principio.

Por otra parte, la utilización de diferentes fuentes -legislativa, doctrinal y documental- ha permitido observar la evolución de esta institución en los siglos XVIII y XIX, permitiéndonos comprender que los saltos legislativos producidos, especialmente la promulgación del primer Código de Comercio español en 1829, no se traduce en una transformación legislativa. La regulación del proceso arbitral se mantiene incólume a las discontinuidades legislativas, sin que puedan apreciarse transformaciones rupturistas.

\section{FUENTES DOCUMENTALES Y LEGALES UTILIZADAS}

Partidas de Alfonso X El Sabio

Novísima Recopilación

Archivo Histórico de Protocolos de Sevilla

Archivo de la Cámara de Comercio de Sevilla

Ordenanzas del Consulado de Bilbao de 1737

Ordenanzas del Consulado Nuevo de Sevilla 1784

Proyecto de Ordenanzas del Real Tribunal del Consulado de Cádiz 1800

Proyecto de Ordenanzas del Consulado de Málaga 1828

Código de Comercio 1829

\section{BIBLIOGRAFÍA}

ABÁsolo, Ezequiel (2008-2009), "El código de comercio español de 1829 en los debates y las prácticas jurídicas del extremo sur de América", Anuario de Historia del Derecho Español, 78-79, pp. 447-460.

Cervantes Bravo, Irina (2015), "La justicia alternativa en la Constitución de Cádiz y su influencia en el constitucionalismo mexicano", en E. A. López SÁnchez y J. L. Soberanes Fernández (coords.), La constitución de Cádiz de 1812 y su impacto en el occidente novohispano, Universidad Nacional Autónoma de México-Instituto de Investigaciones Jurídicas, México D. F., pp. 153-17.

Fernández de Buján, Alberto (2011), Derecho público romano: recepción, jurisdicción y arbitraje, Thomson Reuters Civitas, Navarra.

Franch Benavente, Ricardo (1986), Crecimiento económico y enriquecimiento burgués en la Valencia del siglo XVIII, Alfons el Magnanim, Valencia.

GonzÁlez Huebra, Pablo (1867), Curso de Derecho Mercantil, Librería de Sánchez, Madrid. 
Grossi, Paolo (2009), "Note introduttive: vocazione corporativa e vocazione globale del diritto commerciale", en S. Rossi y C. SтоRTі (a cura di), Le matrici del diritto commerciale tra storia e tendenze, Insubria Universtity Press, Bari (Italia), pp. 9-18.

Heredia Herrera, Antonia (1985), "El consulado nuevo de Sevilla y América”, en Actas de las V jornadas de Andalucía y América, Universidad Internacional de Andalucía, La Rábida (Huelva).

Hinojosa Segovia, Rafael (1991), El recurso de anulación contra los laudos arbitrales, Revista de Derecho Privado, Madrid.

Jimeno-Borrero, Jesús (2020), La compañía de comercio sevillana entre 1747 y 1848, Diputación Provincial, Sevilla.

Ortego Gil, Pedro (1999), "Lo gubernativo y lo contencioso en los consulados borbónicos", Dereito. Revista Xurídica da Universidade de Santiago de Compostela, 8, 2, pp. 167-201.

Mora CañAdA, Adela (1988), "El Tribunal del Consulado Tribunal del Consulado de Valencia en el siglo XVIII: conflictos de competencias y legislación aplicable en los procesos", en Homenaje a Juan Berchamans Vallet de Goytisolo, vol. II, Consejo General del Notariado, Madrid, pp. 629-638.

Martone, Luciano (1984), Arbiter-Arbitrator. Forme di giustizia privata nell'etá del diritto commune, Nápoles, pp. 72-127.

Petit, Carlos (2016), Historia del derecho mercantil, Marcial Pons, Madrid.

- (2013a), "El código de comercio de Sainz de Andino: Algunos antecedentes y bastantes críticas", Revista de Derecho Mercantil, 289, pp. 109-151.

- (2013b), "El legislador y la biblioteca. Los fondos de Andino en la Universidad de Sevilla", Glossae, European Journal of Legal History, 10, pp. 489-506.

- (1980), La compañía mercantil bajo las ordenanzas del Consulado de Bilbao 1737-1829, Universidad, Sevilla.

PÉrez Royo, Vicente (2016), “El arbitraje en la documentación medieval valenciana. La caracterización de la institución arbitral en la práctica documental de las comarcas de Els Ports y El Maestrat entre 1232 y 1412", Anuario de Historia del Derecho Español, LXXXVI, pp. 145-195.

Vicente, José de (1842), Nuevo Manual de Práctica Forense, Imprenta de Omaña, Madrid. 